\title{
¿Son posibles otras educaciones para indígenas dentro del sistema escolar tradicional? Análisis de un caso en el nordeste argentino*
}

\author{
ARE OTHER FORMS OF EDUCATION POSSIBLE FOR INDIGENOUS PEOPLE WITHIN THE TRADITIONAL \\ SCHOOL SYSTEM? CASE ANALYSIS IN NORTH EASTERN ARGENTINA
- SÃO POSSÍVEIS OUTRAS EDUCAÇÕES PARA INDÍGENAS DENTRO DO SISTEMA ESCOLAR TRADICIONAL? ANÁLISE DE CASO NO NORDESTE ARGENTINO

\author{
Teresa Laura Artieda* \\ Tatiana Sabrina Barboza**
}

\section{Resumen}

El presente artículo presenta un análisis del proceso de demanda de autonomía que adelantan actualmente organizaciones qom, wichí y moqoit en la provincia del Chaco, nordeste de Argentina. Estas organizaciones aspiran al manejo de las escuelas del sistema estatal a las que asisten sus miembros y así ganar libertad para construir sus propias propuestas en educación. El trabajo comienza con una presentación sucinta del escenario étnico-político para ubicar el presente del proceso en perspectiva histórica y regional. Posteriormente, presenta la narración de las deliberaciones que culminaron en la sanción normativa que regula la autonomía buscada, las demandas en las voces de indígenas participantes, los sentidos de la legislación, divergencias, oposiciones, logros y límites del proceso. Se pasa a problematizar el campo conflictivo en el cual Estado y pueblos indígenas en lugar de aparecer cada uno como bloque homogéneo confrontado, expresa desacuerdos internos; $y$, finalmente, trata desafíos, posibilidades y condicionantes de la autonomía gestada desde abajo para ser reconocida por el Estado y desenvolverse dentro de la escolarización oficial. Para el estudio, se trabajó con normativas provinciales, proyectos de ley, diarios locales, registros de campo y entrevistas a funcionarios ministeriales y a docentes indígenas involucrados.

\section{Palabras clave}

autonomía indígena; escolarización; legislación y derechos; tensiones y logros

\footnotetext{
* El trabajo se enmarca en la investigación PICT-O UNNE 224, "Historia de accesos y exclusiones a la cultura escrita en la Argentina. Concepciones, políticas y prácticas. Entre la Colonia y el siglo XXI". Facultad de Humanidades. Universidad Nacional del Nordeste (UNNE). Argentina.

** Universidad Nacional del Nordeste, Instituto de Investigaciones en Educación, Corrientes, Argentina. Correo electrónico: tereartieda@gmail.com

*** Universidad Nacional del Nordeste, Instituto de Investigaciones en Educación, Corrientes, Argentina. Correo electrónico: tatianabarboza@gmail.com
} 


\section{Abstract}

This article presents an analysis of the current process of demand for autonomy by the qom, wichí and moqoit organizations in the province of Chaco in northwestern Argentina. These organizations aspire to manage the state schools attended by their members and thus be free to build their own proposals on education. The paper begins with a brief presentation of the ethnic-political scenario in order to contextualize the process from a historical and regional perspective. This is followed by an account of the deliberations that culminated in the normative sanction governing the autonomy sought, the demands of the indigenous participants, the meanings of the legislation, divergences, oppositions, achievements and limits of the process. Then, the conflictive field where the State and indigenous people express internal disagreements instead of appearing as homogenous, confronted blocks is problematized. Finally, the paper addresses the challenges, possibilities and conditions of autonomy born from below to be recognized by the State and to develop within official schooling. To perform the analysis, we worked with provincial regulations, bills, local newspapers, field records, and interviews with ministry officials and indigenous teachers involved.

\section{Resumo}

O presente artigo apresenta uma análise do processo de demanda de autonomia que organizações gom, whichi e moqoit, na província do Chaco, nordeste da Argentina, realizam atualmente. Estas organizações visam gerenciar as escolas do sistema estadual frequentadas por seus membros, adquirindo assim a liberdade para construir suas próprias propostas em educação. $\mathrm{O}$ trabalho inicia com uma apresentação sucinta do cenário étnico-político para localizar o processo em perspectiva histórica e regional. Posteriormente, apresenta-se a narração das deliberações que finalizaram na sanção estabelecida que regula a autonomia desejada, as demandas nas vozes dos indígenas que participam, os sentidos da legislação, divergências, oposições, conquistas e limites do processo. Problematiza-se o campo conflitivo no que o Estado e os povos indígenas ao invés de aparecer cada um como bloque homogêneo confrontado, expressa discordâncias internas; e, finalmente, abordamse desafios, possibilidades e condições da autonomia gestada desde abaixo para ser reconhecida pelo Estado e povos e se desenvolver dentro da escolarização oficial. Utilizaram-se, neste estudo, normativas provinciais, projetos de lei, jornais locais, diários de campo e entrevistas a trabalhadores ministeriais e professores indígenas envolvidos.

Fecha de recepción: 29 de julio de 2016 / Fecha de aprobación: 04 de octubre de 2017

\section{Keywords}

indigenous autonomy; formal education; legislation and rights; tensions and achievements

\section{Palavras chave}

autonomia indígena; escolarização; legislação e direitos; tensões e conquistas 


\section{Notas de contexto}

En Argentina desde el advenimiento de la democracia en la década de 1980, los indígenas han adquirido importantes derechos en el plano jurídico. Las reformas de la Constitución Nacional y la del Chaco en 1994 determinaron el reconocimiento de la preexistencia étnica y cultural de los pueblos indígenas, el respeto a su identidad y el derecho a una educación bilingüe e intercultural, el reconocimiento de la personería jurídica de sus comunidades, la posesión y propiedad comunitarias de las tierras tradicionalmente ocupadas por ellos, entre otros.

Las demás normativas existentes han ratificado y ampliado estos derechos. Mencionamos el Convenio de la OIT sobre Pueblos Indígenas y Tribales adoptado por el Estado nacional por Ley No. 24.071/92, la Ley Nacional No. 23.302/85 de Política Indígena y apoyo a las comunidades aborígenes de Argentina; y en la provincia del Chaco la Ley de Comunidades Aborígenes No. 32.58/87, y la Ley No. 6.604/10 de Oficialización de las Lenguas Indígenas.

En el Chaco' 141.304 personas se reconocen como indígenas sobre una población total de 1.055.259; por lo que constituyen casi el $4 \%$ de dicho total 2 . De los 41.304, el 95,1\% es descendiente de los pueblos originarios que históricamente han habitado esa región: el 74,5 \% pertenece al pueblo Qom, el 11,2 \%, al Wichí y el 9,4\%, al Moqoit 3 .

En cuanto a las estadísticas educativas provinciales sobre matrícula indígena de los últimos años, en 2008, 115 alumnos asistían al nivel superior no universitario, frente a 12.411 en el nivel primario y 602 en el secundario. En 2014, 12.106 alumnos se encontraban matriculados en el nivel primario, 2.712 en el nivel secundario y 644 en el nivel superior no universitario. Se observa un notable aumento en la matrícula del nivel secundario y del nivel superior no universitario ${ }^{4}$. Sin embargo, se mantiene

1 Estado provincial ubicado en el nordeste de la República Argentina, que integra la región del Gran Chaco sudamericano la que abarca parte del norte de Argentina, este de Bolivia, oeste del Paraguay y sur de Brasil. Con la actual provincia de Formosa, fue el último territorio indígena conquistado por el Estado nacional entre 1884 y 1911.

2 Según datos oficiales, la población indígena representaría el 3,91 $\%$ de la población total. En: Argentina, INDEC, Censo Nacional de población y viviendas, 2010.

3 Argentina, INDEC, Censo Nacional de población y viviendas, 2010.

4 Atribuimos este aumento, entre otras razones, a la obligatoriedad del nivel medio establecida por Ley de Educación Nacional No. 26.606/2006, y a políticas de asistencia económica del Gobierno nacional que favorecieron la baja matrícula indígena (histórica) en los niveles medio y superior no universitario respecto del primario. Según los datos presentados, la matrícula del nivel secundario representa el $22 \%$ de la matrícula del nivel primario, en tanto que la de nivel superior no universitario solo representa un 5\% de la misma (644/12.106). 5 Respecto al número de docentes indígenas que trabajan en el sistema educativo provincial, la última estadística disponible data de 2011 y registra un total de 194 indígenas de los tres pueblos mencionados.

Debe decirse que el Chaco se distingue del resto de provincias de Argentina "por ser una de las pioneras en el reconocimiento indígena y por su numerosa legislación al respecto, desde fines de la década del 80 y principios de los 90" (Hecht, 2014). También ocupa un lugar sobresaliente en el concierto nacional, con relación a los avances en educación bilingüe intercultural (EBI). La citada Ley de las Comunidades Aborígenes de 1987 constituyó un piso jurídico de reconocimiento de derechos y operó como marco de las demandas posteriores en esta provincia. En el campo educativo, las regulaciones contenidas en el capítulo sobre cultura y educación dieron origen a la EBI, porque establecieron el derecho de los pueblos indígenas a educarse en su lengua y su cultura, y determinaron la formación de docentes indígenas y la incorporación de pedagogos indígenas en aulas con niños de esos pueblos. A partir de este hecho, se desarrolló una historia de casi treinta años en materia de EBI, que no estuvo exenta de ambigüedades, contradicciones y conflictos. Una constante que atraviesa esta historia es la presión de los pueblos indígenas para incidir en su configuración (Artieda, Liva y Almirón, 2014; Hecht, 2014). Al mismo tiempo, es posible afirmar que la educación para/de estos pueblos en el Chaco se fue definiendo en un campo de diálogos, negociaciones, concesiones y disputas entre pueblos indígenas, Estado, iglesias y organizaciones no gubernamentales. Este fenómeno es crecientemente visible cuando menos desde los años 1960 (Artieda, Liva y Almirón, 2014).

Entre los comienzos de la EBI y la actualidad se registran logros notorios. Se pasó de indígenas que se desempeñaban como auxiliares de los docentes no indígenas, y de

condiciones de acceso a este nivel que se aplicaron a partir de 2009 y 2014 en todo el país (Rosso, Artieda y Luján, 2016).

5 Síntesis estadística extraída de Rosso, Artieda y Luján (2016). 
la inclusión de la lengua y la cultura como contenidos paralelos a los del currículo oficial, a maestros y profesores indígenas a cargo de las aulas y, en años recientes, algunos de ellos se encuentran en el ejercicio de cargos directivos en escuelas de enseñanza inicial y básica de la modalidad. Así mismo, comenzaron a acceder a direcciones de escuelas de enseñanza media y superior. En la actualidad, docentes indígenas integran la estructura ministerial dentro del área de educación encargada de la EBI dentro de la Subsecretaría de Interculturalidad y Plurilingüismo creada en 2010 (Decreto No. 380/2010). Desde 2012 se cuenta con un currículo específico para la educación inicial, primaria y de adultos y educación media ${ }^{6}$. El acceso a derechos en materia educativa incluye el ingreso a estudios universitarios -aunque en las carreras de grado convencionales de la Universidad regional- por medio de un programa de becas y otras modalidades de asistencia, desde 2011. En 2016 se graduaron las dos primeras becarias indígenas (Rosso, Artieda y Luján, 2016)7.

Es posible calibrar los avances de la EBI en el plano jurídico a través de lo dispuesto en dos leyes generales de educación del Chaco sancionadas en un lapso que media entre 1998 y 2010. La Ley 4.449/98 establece la libertad de los pueblos indígenas para crear escuelas. Sin embargo, es una libertad ficticia porque no responsabiliza el Estado como garante del financiamiento así como no define mecanismos de participación de estos pueblos en las decisiones de política educativa que los conciernen. Por el contrario, la Ley No. 6691/2010 establece a la EBI como modalidad por medio de la cual debe asegurarse el derecho a la educación de los pueblos indígenas (cap. XIII, art. 87 a 89). Compromete al Estado en su financiamiento, así como lo obliga a crear mecanismos que aseguren la participación de estos pueblos en la definición de políticas educativas que los atañen. Se los considera parte del conjunto de actores responsables de las acciones educativas de la provincia en un pie de igualdad con los Estados provincial y nacional, las confesiones religiosas, las organizaciones

6 Los primeros Diseños Curriculares para la Educación Bilingüe e Intercultural fueron aprobados por la Resolución Ministerial No. 10.469 de 2012.

7 Para una sintética reconstrucción de la historia de la EBI en el Chaco, véase Artieda, Liva y Almiron (2014), Hecht (2014) y Ramírez (2014). Respecto del acceso a estudios universitarios, véase Rosso, Artieda y Luján (2016). sociales y la familia (art. 6), y reconoce su libertad para promover la creación de instituciones de enseñanza (art. 14). Entre las modalidades de gestión de los establecimientos, reconoce la "gestión social indígena" (cap. II, art. 23). 8 En 2014, el parlamento del Chaco sanciona la Ley No. 7.446 que regula los derechos específicos enunciados en la norma anterior. El proceso que condujo a la sanción y su denominación, Ley de Educación Pública de Gestión Comunitaria Bilingüe Intercultural Indígena, condensan una densidad de sentidos que intentaremos desplegar de manera parcial en las páginas siguientes. Antes de abocarnos al tema, es necesario advertir que así como la primera de las leyes mencionadas, de 1994, fue aprobada en un contexto de hegemonía neoliberal, agudo empobrecimiento de amplios sectores de la población y debilitamiento de los movimientos indígenas por efecto de tal hegemonía, distinto es el momento en el que se sancionan las leyes de 2010 y 2014. En esos últimos años tuvo lugar en el Chaco un conjunto de procesos disruptivos que modificaron las relaciones entre el Estado provincial y los pueblos indígenas y reconfiguraron el campo étnicopolítico. Importantes movilizaciones difundieron las condiciones críticas de vida, reivindicaron el acceso a la tierra, y llevaron el conflicto hasta la Corte Suprema de Justicia de la Nación, la que a través de una orden obligó a los Estados nacional y provincial a garantizar a los indígenas el cumplimiento de sus derechos, y obligó a mayor presencia indígena en instancias decisorias y en organismos estatales de las áreas de salud, justicia, vivienda y educación (Rosso, Artieda, Luján, 2016).

\section{El camino hacia la sanción de la ley}

Como adelantamos, entre 2010 y 2014, en el Chaco transcurre el breve lapso entre la sanción de la ley provincial de educación que reconoce escuelas de

8 La norma provincial es congruente con la Ley de Educación Nacional No. 26.606/2006 en cuanto a las prescripciones que hemos mencionado sobre la EBI. De igual manera, la figura de escuelas de gestión social está reconocida por la ley nacional; implica el derecho de organizaciones sociales diversas -por ejemplo, movimientos sociales surgidos de las luchas contra las políticas neoliberales de los años 1990, fábricas recuperadas por sus trabajadores, organizaciones barriales, cooperativas, entre otras, de proponer la creación y de gestionar establecimientos escolares. Es en la legislación educativa del Chaco donde se agrega la cualidad de indígena a ese tipo de gestión, y se enfatiza la obligación estatal de su financiamiento. 


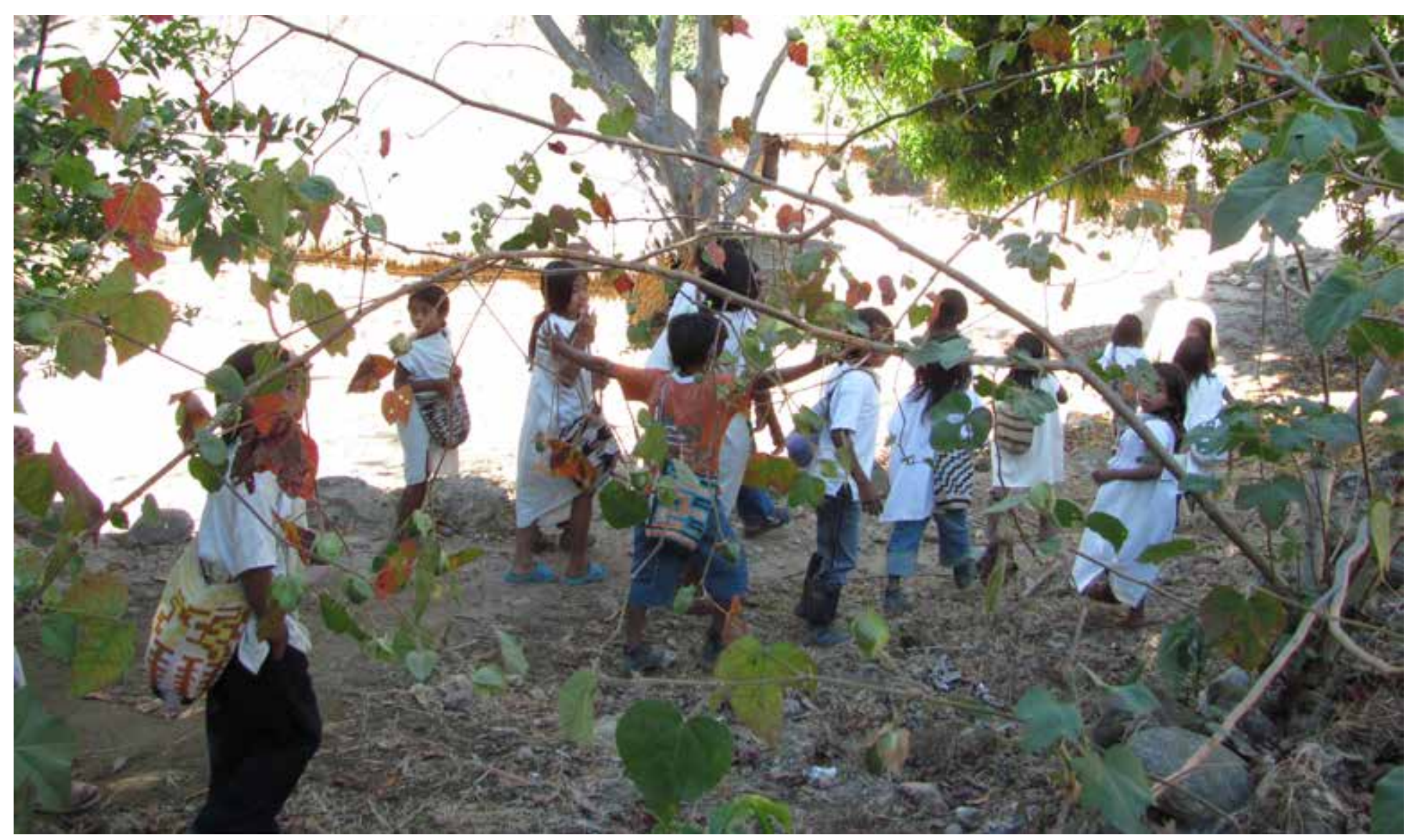

Enyel Esteban Rodríguez García » Sierra Nevada de Santa Marta, Centro Educativo de Cherua » Resguardo del Pueblo Wiwa » 15 de enero de 2012 
gestión social indígena y compromete el sostenimiento estatal, la No. 6.691, y la sanción de la ley que regula las mismas, la No. 7.446.

Entre el punto de partida y el de llegada lo que hubo fue un debate sostenido por una fuerte presencia indígena que logró ensanchar los límites instituidos por la monocorde lógica colonial. En ese debate, los indígenas participantes se valieron de los intersticios ya instituidos en la regulación nacional (las mencionadas escuelas de gestión social reconocidas en la regulación nacional y especificadas para los indígenas en la norma provincial), y de prácticas existentes en la tradición escolar argentina como las habilitaciones de que goza la educación privada (autonomía en la selección del personal de los establecimientos y en la definición de los contenidos). A la vez que apelaron al principio de política educativa de Argentina por la cual se garantiza el financiamiento estatal de las escuelas, en todos los niveles de enseñanza.

Los indígenas esgrimieron incansablemente las normativas provinciales, nacionales e internacionales que prescriben su injerencia en los asuntos que les competen. Sostuvieron los debates, los petitorios y las propuestas que redactaron, con la autoridad que les confiere una experiencia provincial de casi veinticinco años de escuelas más lejanas o más cercanas a un pensamiento colonial, o a un camino que intenta reparar en algún grado la herida colonial (Santos, 2010). Con los conocimientos acumulados a raíz de las prácticas de lucha por la conquista de derechos en general, y en materia educativa en particular?.

Intervinieron a favor organizaciones no indígenas con las que los indígenas comparten, en distintas medidas, concepciones, proyectos e historias. Encontraron una coyuntura favorable como lo fueron, entre las principales, una línea política provincial que tendió al reconocimiento de derechos y la admisión pública de

9 "Cuando hay un proyecto de ley, cuando se tocan intereses indígenas las comunidades siempre reclaman que se haga la consulta, ya sea de salud, de vivienda, de educación, de cualquier tema que afecte los intereses indígenas se pide que se realice la consulta, y zen qué consiste la consulta? Los legisladores se tienen que trasladar a Castelli, a Pampa del Indio, a Sáenz Peña e informar de qué se trata el proyecto." Testimonio de DA. masacres cometidas por el Estado10; y la presencia de funcionarios del Ministerio de Educación inclinados a la consulta, a la participación, y que tomaron nota de la reconfiguración del campo étnico-político provincial: "Este proceso de no solamente pedir un derecho sino salir a conquistarlo que tuvieron las comunidades también nos marcó un tiempo 'ojo que ya se terminó la paciencia de los mansos'" (testimonio de M).

Confrontaron con quienes dentro del sistema escolar y del sistema político más amplio, son parte del entretejido de relaciones de colonialidad: ciertos sindicatos docentes, determinados integrantes de la legislatura, técnicos docentes, entre los actores visibles, expresaron los anticuerpos que genera el sistema escolar frente al riesgo de formatos que corren los límites de lo permitido e intentaron entonces regularlos, ponerles barreras.

El recorrido entre el punto de partida y el de Ilegada entonces no fue llano, como es de esperar, por los factores antedichos. También por las diferencias entre los grupos indígenas participantes, el reclamo de quienes no se vieron suficientemente representados en instancias decisivas de discusión y redacción, y la decisión de relegar los desacuerdos frente a la posibilidad de lograr un instrumento legal que produciría ampliaciones en lo político que afectarían positivamente a todos.

Narramos sumariamente el proceso que explica la síntesis precedente. Una vez aprobada la norma que regulaba la educación de la provincia en sus distintos niveles y modalidades, y reconocía un lugar principal a los indígenas según se mencionó al principio (la Ley No. 6.691/2010), estos se abocaron a obtener una regulación específica que delimitara lo referente a las escuelas de gestión indígena (la Ley No. 7.446/2014). Entre los asuntos preponderantes, era necesario definir quiénes podrían atribuirse la creación, las formas de gobierno, la designación del personal docente, el financiamiento, es decir, las maneras de asegurar la intervención de organizaciones y comunidades indígenas en los establecimientos.

\footnotetext{
10 En 2007, el Estado provincial pidió disculpas públicas por la Masacre de Napalpí, cometida en 1924 por fuerzas policiales en la localidad del mismo nombre, donde asesinaron a cientos de mujeres, hombres, niños y niñas Moqoit y Qom.
} 
La cuestión mereció seis anteproyectos, el primero presentado por el Poder Ejecutivo, tres redactados por asociaciones indígenas, otros dos elaborados por partidos políticos representados en la legislatura del Chaco ${ }^{11}$. Las diferencias entre los de autoría indígena y los dos últimos estribaban sobre todo en el grado de autonomía reservado a los indígenas, y en el consiguiente reconocimiento del valor de sus prácticas culturales ${ }^{12}$.

Las discusiones adquirieron estado público debido a la entidad de los participantes y a las modalidades y ámbitos donde tuvieron lugar. En las mismas estuvieron involucrados el Estado provincial a través de legisladores, funcionarios y técnicos del Ministerio de Educación; sindicatos mayoritarios que agrupan a docentes no indígenas, organizaciones y docentes indígenas, y asociaciones civiles que trabajan con estos últimos. Las discusiones demandaron numerosas reuniones entre las que destacamos las que tuvieron lugar con los diputados 13 , incluyendo la sesión de debate y aprobación, y con representantes de los sindicatos.

La envergadura de lo que estaba en juego ameritaba el estado público que tomó, el tiempo que llevó lograr la aprobación de la ley, y las disputas que acaecieron.

Los sindicatos mayoritarios asumieron posiciones contrapuestas, dos se opusieron y el tercero acompañó

11 Proyecto de Ley No. 4.372/2010 de Educación Pública de Gestión Social Indígena del Poder Ejecutivo provincial; Proyecto de la Comisión de Educación, Cultura y Biblioteca Legislativa de representantes del partido radical, 2010; Proyecto de la Comisión de Educación, Cultura y Biblioteca Legislativa de representantes del partido peronista, 2010; Anteproyecto No. 4.372 de Ley de Educación Pública de Gestión Comunitaria Indígena. Comisión de Seguimiento, 2012; Propuesta de Ley de Educación Pública de Gestión Social Indígena, Asociación Civil Consejo Originario de Representantes Sociales y Comunitarios del Gran Barrio Toba Nañoxoc, 2012; Proyecto de Ley Educación Pública de Gestión Comunitaria Indígena. L'QataxacNamQompi y Asociación Civil Che'Eguera, 2012. El proyecto que resultó aprobado en 2014 integra aspectos de los aquí enumerados.

12 Por ejemplo, mientras que los proyectos elaborados por los indígenas asignaban a sus organizaciones la elección de los docentes, uno de los partidos políticos reservaba la atribución exclusivamente al Ministerio de Educación. Para un análisis de los proyectos, véase Artieda, Liva y Almirón (2012).

13 Entre otras, las "Jornadas de Debate sobre Educación Pública de Gestión Social Indígena", resoluciones No. 1867 y No. 2044/2011 de la Cámara de Diputados; las Jornadas se realizaron en 2011 y 2012. También reiteradas reuniones con diputados de todos los partidos políticos y entrega de petitorios. las demandas indígenas. La defensa de las fuentes de trabajo de los docentes criollos aparecía como una de las objeciones más importantes de los opositores. La posibilidad de que las comunidades pudieran elegir sus propios maestros, y de esa manera desplazar docentes criollos de sus puestos de trabajo, era el peligro expresado (Datachaco.com, 2013). Pero ¿sólo inquietaba la eventualidad del traslado o el temor se agigantaba debido al peso que tendrían los indígenas en la decisión?14 Para esbozar conjeturas es necesario medir la dimensión del "peligro". Para la fecha de estas discusiones, fines de 2013, los docentes de la provincia del Chaco sumaban poco más de 32.000. En 2011, los docentes indígenas en ejercicio eran 19715.

En palabras de un dirigente sindical preocupado frente a un hecho que pareciera serle inasible, fuera de control:

El primer aspecto que no está claro (en los proyectos) es cómo es la integración de una cultura con otra. No es un tema fácil de debatir si los aborígenes van a quedar absorbidos por la cultura nuestra o lo que refleja la ley, que tienen tanta independencia que quedan fuera de un proyecto nacional, argentino. Prácticamente tienen soberanía sobre lo que es educación. Me parece que no tiene que ser ni un extremo ni el otro: ni absorbidos por una cultura del criollo pero tampoco tener la soberanía para hacer una educación absolutamente diferente de lo que puede ser un proyecto nacional 16 .

14 Según la secretaria general de uno de los sindicatos opositores: "Se va a ver seriamente amenazada la estabilidad de los docentes criollos si se genera la creación de las escuelas de gestión social indígena porque lo que se prevé es que las mismas estén conformadas absolutamente con todos sus integrantes por aborígenes tanto docentes como los que no lo son, porque se incluye la figura del idóneo de las comunidades para que formen parte de (estas) escuelas ... donde el Ministerio va a tener 'cero grado' de definición porque las definiciones para su conformación y para todo serían de parte de las comunidades indígenas." Citado en Artieda (2013).

15 Datos del Área de Educación Aborigen Intercultural Bilingüe del Ministerio de Educación, Cultura, Ciencia y Tecnología. Ese número incluye auxiliares docentes aborígenes, maestros y profesores bilingües interculturales, habilitados para trabajar en la enseñanza primaria. En 2014, la matrícula indígena de ese nivel era de 12.106 alumnos indígenas, lo que trasparenta el hecho de que no toda esta población escolar tenía la enseñanza de maestros de sus pueblos. En el nivel secundario, esta matrícula era de 2.712 personas. (Ministerio de Educación, Cultura, Ciencia y Tecnología, 2014).

16 Citado en Artieda (2013). 
No fueron referentes sindicales los únicos contrarios a la iniciativa de los indígenas. El funcionario a cargo del ministerio alude también a

[...] otras voces que se erigían para decir: ‘No tienen la madurez necesaria como para asumirlo', y a mí me resultó... muy chocante esta frase, porque era como si nos dijeran: 'Son niños y todavía necesitan ser tutelados', ésa es una de las formas de colonización cultural. (testimonio de M).

Para Santos (2010), el pensamiento occidental moderno divide la realidad social en dos universos,

[...] el universo de "este lado de la línea" y el universo del "otro lado de la línea". La división es tal que el "otro lado de la línea" desaparece como realidad, se convierte en no existente, y de hecho es producido como no existente. No existente significa no existir en ninguna forma relevante o comprensible de ser. [...] Fundamentalmente lo que más caracteriza al pensamiento abismal es... la imposibilidad de la copresencia de los dos lados de la línea. (pp. 11, 12 y 14).

La declaración del dirigente sindical, arriba transcripta, pone en evidencia esa imposibilidad de concebir la copresencia.

El debate hizo evidente que el pensamiento colonial estaba siendo sacudido, y que la invisibilidad se encontraba en un ininterrumpido y obstinado proceso de emergencia. En las discusiones con los gremios opositores, algunos de los Qom participantes se pronunciaba de esta manera:

Han pasado 200 años de historia en Argentina y estos indígenas ahora empiezan a caminar, empiezan a ver las reales pertenencias que les corresponden, que les fueron quitadas anteriormente... Nosotros... los indígenas queremos ser protagonistas, queremos ser personas representativas no más de segunda o tercera categoría, nosotros no queremos más marginación racial.

Queremos una escuela propia, con nuestra manera de organizarnos, de pensar y no tenemos que discutir mucho. Yo creo que a esta altura nadie tendría que estar interfiriendo en las discusiones, en nuestro andar. Yo creo que este proyecto deberíamos aprobar para que los pueblos indígenas tengamos una educación propia para nuestros niños ${ }^{17}$.

Mencionamos al principio que no puede concebirse a los indígenas como un bloque homogéneo. Los mismos intervinieron a través de estructuras de representación preexistentes incorporadas al aparato estatal provincial, y por medio de asociaciones comunitarias no insertas en esas estructuras y que sostienen cuestionamientos respecto de la legitimidad de aquellas.

En el primer caso, la representación fue asumida por una comisión de docentes designada por el Instituto del Aborigen Chaqueño, organismo creado por el Gobierno provincial en 1987, y conducido por un directorio integrado por miembros de los tres pueblos ya mencionados ${ }^{18}$. A su vez, la comisión estuvo coordinada por una funcionaria no indígena, responsable del área de educación plurilingüe intercultural del Ministerio de Educación ${ }^{19}$. En el segundo, se trataba de dos organizaciones vinculadas con experiencias anteriores de gobierno escolar en concurso con el estado provincial20; además de otras organizaciones que agrupaban a docentes o líderes comunitarios.

Los dos docentes entrevistados, pertenecientes a las organizaciones del segundo tipo, coinciden en críticas a la tarea de la comisión nombrada en primer término dando cuenta de la reducción paulatina de la consulta y de la interferencia de intereses ajenos a los propósitos colectivos.

Con el tiempo este grupo de docentes se fue encerrando solo, ya decidían ellos, ya no convocaban a la comunidad, ellos como eran todos docentes ya no querían (la consulta) (testimonio de DA).

17 Registro del debate entre referentes indígenas, dirigentes de sindicatos docentes y legisladores de la Comisión de Educación del parlamento, agosto 2013 (en adelante Registro, 2013).

18 El Instituto del Aborigen Chaqueño fue creado por la Ley 3.258/1987 ya nombrada "con la finalidad de atender a la promoción integral del aborigen chaqueño y dar cumplimiento a la presente ley" (art. 22). Está gobernado por un directorio compuesto por vocales de los tres pueblos, que son elegidos por voto directo (cap. VIII, art. 26 a 36).

19 Comisión de Seguimiento de Proyectos de Ley que guarden relación con la Educación Bilingüe Intercultural".

20 Acerca de la experiencia de una de esas organizaciones, L'QataxacNamQompi /Consejo Qompi,de gobierno escolar en concurso con el ministerio de educación desde el año 2000, véase Artieda, Liva y Almirón (2014). 


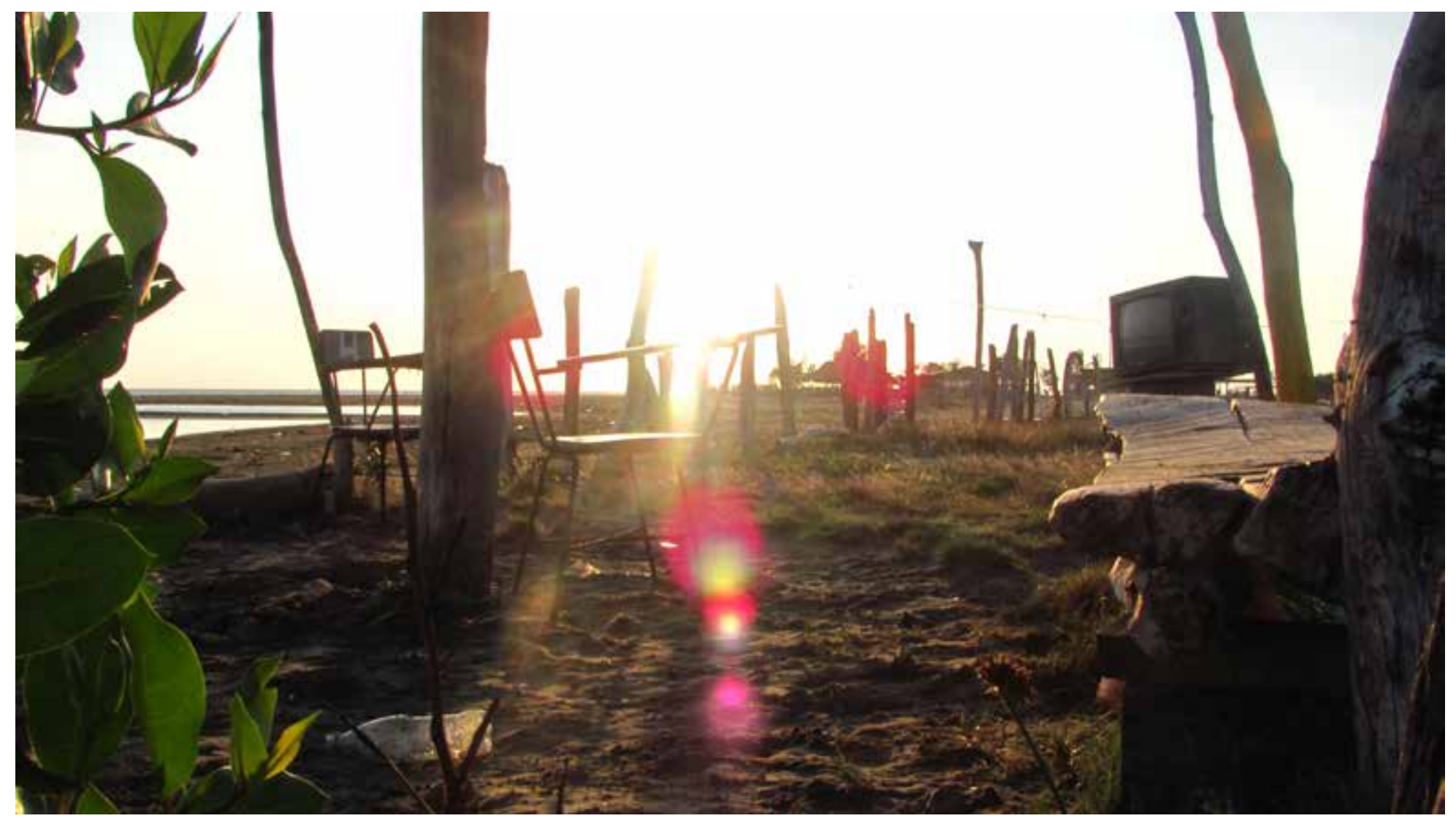

Enyel Esteban Rodríguez García » Cartagena, La Boquilla » Sintonizando el Atardecer. » 21 de marzo de 2011 
A la ley de gestión hemos aportado muchas cosas..., pero después eso se politizó, entró en el juego de la política y nosotros miramos desde afuera, y se ha desmenuzado mucho, se han puesto conveniencias legales de algunos hermanos que están dentro, pero bueno... ésa es la crítica que tenemos, que se salió del espíritu que se quería emprender con la lucha que se inició en el Barrio Toba (testimonio de AN).

Estos testimonios aluden a la incidencia de partidos políticos en el campo de los movimientos étnicos 21 , y a docentes indígenas más cercanos a un pensamiento y una práctica donde prima la preservación de posiciones laborales por sobre proyectos educativos que nutran los propósitos comunitarios: "Conveniencias legales de algunos hermanos que están dentro". Dicho en otros términos, son voces que alertan respecto de que el pensamiento colonial no está solamente del lado de los no indígenas. Y, seguimos discurriendo, la escolarización por la que transitaron estos docentes indígenas tiene que ver con esa realidad.

Parte de la problematización acerca de las posibilidades y límites de otras educaciones consiste en profundizar el conocimiento respecto de tales cuestiones. Para emprender esa tarea, en relación con el presente caso es necesario relevar la policromía de voces intervinientes. Las aquí transcriptas provienen de dos de las organizaciones participantes.

\section{Los sentidos en juego y lo prescripto}

Ilustraremos acerca de algunas cuestiones nodales que nos permitan transmitir los sentidos de autonomía y de escuela propia que estuvieron en juego.

La sustitución de la denominación de gestión social por gestión comunitaria es una de ellas. En parte, lo que aquí se traslucía, siguiendo los testimonios recabados, fue la necesidad de evitar una denominación que diera lugar a equívocos respecto de quiénes tendrían atribuciones

21 Es de advertir que el último tramo de estas deliberaciones y la aprobación de la ley son hechos simultáneos al proceso de renovación de autoridades indígenas del Instituto del Aborigen Chaqueño antes mencionado, proceso atravesado por vínculos con los partidos políticos con representación en el Gobierno y el parlamento de la provincia. para proponer y gestionar esas escuelas. La primera denominación alude a organizaciones sociales en general. El término comunitario circunscribe, lo plantean los interesados, a lo indígena ${ }^{22}$. Cuestión que queda prescripta en el articulado: "Tienen derecho a gestionar y a recibir este servicio los pueblos indígenas Qom, Wichí y Moqoit" (art. 6). La atribución excluyente de los indígenas para proponer la creación de escuelas bajo esta norma, fue una cuestión saldada en la normativa.

La expresión educación pública al comienzo de la denominación de la ley busca enfatizar el financiamiento del estado provincial, la gratuidad, el reconocimiento oficial de los estudios y certificaciones, entre los aspectos propios de la educación pública estatal en Argentina.

El carácter bilingüe aparece como una cuestión crítica. Preocupa la enseñanza de los idiomas indígenas frente a la disminución de hablantes de estas lenguas. Sobre todo, ante el hecho de que tampoco la hablan todos los docentes indígenas. De ahí, la intención de que se prescribiera su enseñanza y el compromiso del Estado de garantizar condiciones al respecto. Uno de los docentes Qom lo manifiesta de esta manera:

Y nosotros un poco era respetar el ámbito educativo nuestro del bilingüismo más que nada, y habíamos aportado esto... de que se enseñara el idioma particularmente qom, [...], y tendría que Educación (el Ministerio) bajar una línea para que se pueda también implementar, facilitar a nuestros docentes...que puedan cambiar su metodología de enseñanza. Hoy por hoy... no hay una línea concreta de la enseñanza de la lengua qom, para que se le enseñe al niño a hablar qom porque lo que hoy por hoy se está cultivando es el conocimiento pero no la lengua; entonces el niño crece conociendo el mundo indígena pero no sabe hablar el idioma, o sea que estamos en la línea de cualquier universitario criollo sabiendo el tema indígena porque hace su investigación hace su trabajo, pero no sabe hablar el idioma, o sea que nuestros niños están creciendo de la misma manera (testimonio de AN).

22 "A través de los debates, los hermanos, las comunidades hermanas lograron sacar ese término "social" y reemplazarlo por "comunitaria", porque según decían ellos el término "sociedad" es extraño en su cultura; pero, a su vez (esto es una interpretación mía) temían la presencia de movimientos sociales." Testimonio de S. 
La mención expresa al dominio de la lengua entre los docentes solo aparece en un enunciado, el que pauta las condiciones que deberán cumplir los "pedagogos indígenas o sabios" para ser designados en las escuelas: "conocimiento de la lengua y la cosmovisión" (art. 9, inc. a).

El Consejo Comunitario Indígena aparece como la figura principal para asegurar la participación de las comunidades, un modo de incorporar en las escuelas los modos deliberativos.

Es parte de la modalidad, de la ética del pueblo indígena, es algo que siempre estuvo presente para poder debatir, para poder construir, para poder desarrollar, para poder encaminar cosas... y el Estado tendría que haber ya facilitado [...] hace mucho, no esperar que se levante la comunidad educativa y que empiece a dar palizas y a hacer una confrontación ¿por qué tenemos que confrontar, llegar a la confrontación? (testimonio de AN).

El Consejo Indígena elige a sus docentes, sus directivos, personal de limpieza..., es una gestión nueva que también es muy rechazada por los sindicatos docentes [...] está conformado por jóvenes, ancianos, no hay figura de presidente, de tesorero; a la hora de votar si hay cincuenta integrantes votan y bueno si gana la mayoría se toma la decisión, pero no hay presidente, no hay secretario, y eso es lo que por ahí muchos no entienden que es una forma tradicional de manejarse (testimonio de DA).

La norma aprobada incorporó estos Consejos. El Consejo gestiona, organiza y conduce el proyecto educativo comunitario "en coordinación con la autoridad escolar" (art. 9, inc.a). La "coordinación" connota ambigüedad respecto del peso de sus decisiones. Entre las cuales se encuentra la elección de los directivos, el personal de limpieza y administrativo y la mitad del personal docente. El Ministerio de Educación propone la otra mitad. A la vez, para la gestión de cada establecimiento se prescribe la toma consensuada de decisiones entre el Ministerio, el Consejo y "la autoridad escolar" (art. 10). Los entrevistados manifiestan su insatisfacción con esta resolución.

Mucho se cambió, y había artículos por ejemplo en donde la decisión del Consejo Indígena era vinculante, y... sacaron la palabra "vinculante", que es el director el que tiene que tomar las decisiones en el establecimiento; no como en Pampa del Indio donde el Consejo (Indígena) sí tiene las decisiones vinculantes 23 , todas las decisiones que ellos toman se acatan, también el Gobierno provincial... No tiene que darle explicaciones si tiene que poner un directivo, o si un docente tiene mal desempeño lo puede cambiar, es lo mismo que una escuela privada que si quiere cambia su plantel docente, en ningún momento el Estado provincial cuestiona las decisiones en una escuela privada, no cuestiona (testimonio DA).

Nociones como autonomía implican diferentes interpretaciones que pueden expresar por ejemplo mayor poder de decisión, desregulación por parte del Estado o privatización, y la lucha por la hegemonía discursiva consiste en fijar el sentido de la palabra (Almandoz y Vitar, 2006). En el caso que estudiamos los indígenas demandan al Estado que les reconozca poder de decisión sobre autoridades y docentes, y la libertad de definición y ejecución de un proyecto educativo propio. Pero, al mismo tiempo, le reclaman que les asegure condiciones para el ejercicio de esa autonomía, tal es el caso de la garantía de financiamiento establecida en la norma ${ }^{24}$. La norma no quita al Estado su poder de regulación. El hecho de haberse reservado la decisión sobre la mitad del plantel docente es un ejemplo, y las escuelas no están eximidas de los controles y supervisiones estatales del resto de instituciones del sistema.

Autonomía significa también aquí que los indígenas puedan desplegar y utilizar nociones y lógicas inspiradas en sus tradiciones y sus memorias. El Consejo de Ancianos como asesores del Consejo Comunitario, los sabios o pedagogos indígenas como parte del grupo de docentes, fueron demandas incorporadas a la ley. De hecho, la consideración de los conocimientos de cada pueblo en el currículum, y la modificación de las efemérides también están comprendidas en esta noción. Para Qom, Wichí y Moqoit importa la conmemoración de líderes indígenas y de eventos significativos. Interesa convertir las efemérides tradicionales, aprovechando

\footnotetext{
23 El docente hace referencia a la experiencia del Consejo Qompi ya mencionado.

24 El artículo 19 postula: "El financiamiento del Estado a la Educación de Gestión Comunitaria Bilingüe Intercultural Indígena figurará específicamente con ese carácter en el presupuesto anual que elabore el Ministerio de Educación, Cultura, Ciencia y Tecnología, discriminado por niveles".
} 
su papel en la creación de conciencia de pertenencia. Interesa su contribución a una conciencia diferente.

El sentido de autonomía comprende la exigencia de que se reconozca la capacidad de producir prácticas pedagógicas propias porque entre los derechos del Consejo Comunitario figura: "Publicar, difundir y registrar experiencias pedagógicas" (art. 9, inc. e). Y lo amplían al derecho de autoría: "[...] elaborar, publicar, patentar y registrar material educativo" (art. 9, inc. f). Como sustrato de esta enumeración reconocemos la experiencia sufrida de despojo de la propiedad de los textos y de los saberes, que recogimos en otras investigaciones, y que se agrega a la histórica expropiación de sus tierras, ríos y vidas (Artieda, Rosso y Ramírez, 2008).

\section{Cierre}

El proceso que se reseña ocurre en el marco de movimientos étnicos que entienden lo educativo inscripto en luchas sociales por ampliación de derechos, y que plantean la necesidad de otras lógicas de gestión, gobierno y organización de los establecimientos escolares. Aparece como una autonomía gestada desde abajo, y definida por organizaciones y comunidades indígenas en términos de márgenes de libertad respecto del Estado (Feldfeber, 2009; Saforcada, 2009), al que presionan para que esta libertad sea sostenida por un ordenamiento jurídico en cuya elaboración ellas sean partícipes ineludibles.

El Estado entonces es un actor inexcusable. Estas organizaciones y comunidades no conciben una situación de desregulación o de privatización tal que signifique que aquel se desentienda del financiamiento, sino que sostienen que eso es precisamente lo que garantiza la autonomía. De modo que se lo interpela para que cumpla con su obligación de asegurarles el ejercicio de los derechos reconocidos por la normativa nacional e internacional a la que este ha adherido. El carácter de lo público en la educación por la que bregan conlleva este principio político, consustancial por otra parte a la gratuidad; e implica además la validación de los estudios y certificaciones.

Esto genera condicionamientos; entre los principales, la constitución de los Consejos Comunitarios Indígenas según normas jurídicas impuestas por el Estado (art. 8 inc. a), la distribución por mitades de la selección de los docentes, y la equiparación del poder de decisión de los Consejos, el equipo directivo y el Ministerio en la gestión de las escuelas.
La autonomía es lo que otorga a los indígenas los márgenes de libertad para decidir docentes, contenidos, modos, materiales de estudio, prácticas culturales. Generar condiciones para subvertir el papel de consumidores pasivos de modos didácticos enseñados por otros, y ejercer la capacidad de desarrollos pedagógicos propios. Para cambiar los lugares estereotipados de informantes de su propia cultura reelaborada, escrita y patentada por otros, y ser reconocidos como dueños y autores de esta. Como graficamos al principio, para hacer una educación con las propias manos. Así lo expresaba el integrante de una asociación civil no indígena participante en uno de los debates en el parlamento, previos a la sanción:

Quiénes de nosotros, no indígenas, podemos decir que les podemos garantizar a ellos calidad educativa si hemos fracasado... Fallamos continuamente en la calidad. Porque no queremos aprender su lengua, no queremos aprender su cultura, y los queremos integrar. Como decía Sixto, déjennos caminar. Lo dijo Feliciano ${ }^{25}$, déjennos pensar. Por qué no pueden pensar una educación y equivocarse. Ya nos equivocamos nosotros 200 años 26 .

Esta intervención anticipa una historia con finales abiertos. Porque lo que se estuvo gestando es en buena medida inédito y va tomando forma en el devenir de las instituciones que comienzan a funcionar con el marco aprobado. Devenir que, es obvio, no puede pensarse Ilano como no lo ha sido su gestación reciente ni los antecedentes en los que se origina. Lo que aquí se ha analizado, de manera parcial, es lo ocurrido durante un tiempo corto e intenso de debates y de sanción de una regulación que instala un nuevo piso político y jurídico a favor del accionar de comunidades y organizaciones indígenas del Chaco. Optamos por el plural, finales abiertos, porque suponemos configuraciones educativas disímiles según los contextos comunitarios y las coyunturas históricas. No somos proclives a definiciones unívocas respecto de educación indígena e intercultural, sino a intelecciones asentadas en terreno. Tampoco podríamos serlo porque acordamos con interpretaciones de identidades étnicas entendidas como configuraciones sociohistóricas dinámicas. Finalmente, porque es imposible negar las mixturas, las hibridaciones surgidas de las décadas de escolarización por las que pasaron los maestros y las maestras Qom, Wichí y Moqoit.

25 Integrantes del Consejo Qompi, ya citado. 26 Asociación Che'Eguera. Registro, 2013. 
Pero también, debemos decirlo por la época en la que escribimos este artículo, porque el presente de Argentina hegemonizado por políticas neoliberales se muestra francamente hostil acerca de condiciones imprescindibles para el debilitamiento de posiciones discriminadoras y el diálogo intercultural. El hecho de que el actual ministro de Educación de la Nación haya nombrado como "nueva Campaña del Desierto, sin espadas" 27 a la política educativa que sustenta, adhiriendo al elegir esa denominación al genocidio emprendido por el Estado nacional en el último cuarto del siglo XIX contra tehuelches, mapuches, ranqueles, pampa, selk'nam y tantos otros del sur del territorio argentino, nos exime de argumentar respecto de la hostilidad que auguramos con relación a la constante e ingente construcción y reconstrucción de los sujetos pedagógicos latinoamericanos que se manifiesta con formas específicas en esta subtropical región del continente.

\section{Referencias}

Almandoz, M.R. y Vitar, A. (2006). Senderos de la innovación: las políticas y las escuelas. En: A. Vitar y D. Zibas (org.) Gestão de Inovações no Ensino Médio (pp. 1-20). Brasilia: LiberLivro-OEI - Fundação Carlos Chagas. Recuperado el 10 de mayo de 2017 de: https://es.scribd.com/document/343838784/Senderos-deLa-Innovacion-Las-Politicas-y-Las-Escuelas.

Artieda, T., (2013). ¡Seño, permiso para descolonizar! En el Chaco los indígenas queremos otra escuela. II Seminario Nacional de la Red Estrado, Red Latinoamericana de Estudios sobre Trabajo Docente, Facultad de Trabajo Social, UNER y Facultad de Humanidades, UNNE. Paraná, Entre Ríos, 12 y 13 de setiembre.

Artieda, T., Rosso, L. y Ramírez, I. (2008). De "salvajes en extinción" a autores de textos. La producción de textos como expresión de conflictos interétnicos. En: T. Artieda (comp.). Los otros en los textos escolares. Conflictos en la construcción de imágenes de nación (pp. 74-116). Buenos Aires: Imprenta de la Universidad Nacional de Luján.

Artieda, T., Liva, Y. y Almirón, V. (2012). La participación de docentes y organizaciones indígenas en los procesos de definición de las escuelas públicas de gestión social indígena en la provincia del Chaco, Argentina. Ix Congreso Internacional de la Red Estrado, Red Latinoamericana de Estudios sobre Trabajo Docente, Universidad de Santiago de Chile, mimeografiado.

Artieda, T., Liva, Y. y Almirón, V. (2014). "Tenemos la fuerza que nos da la comunidad, la organización". Resistencia indígena, escuela media y trabajo docente en el Chaco (1994-2010). En: D. Veiravé (comp.). Mirar la escuela secundaria desde el trabajo docente (pp.83-112). Corrientes: Eudenne.

27 Discurso del Ministro de Educación y Deportes, Esteban Bullrich, durante la inauguración del Hospital Escuela de Veterinaria de la Universidad Nacional de Río Negro, el 15 de septiembre de 2016. En Diario Clarín del 16/9/2016.
Asociación Civil Consejo Originario de Representantes Sociales y Comunitarios del Gran Barrio Toba Nañoxoc (2012). Propuesta de Ley de Educación Pública de Gestión Social Indígena. Chaco.

Cámara de Diputados de la provincia del Chaco (1987). Ley Provincial de las Comunidades Indígenas No. 3.258. Chaco, Argentina.

Cámara de Diputados de la Provincia del Chaco (2010). Proyecto de la Comisión de Educación, Cultura y Biblioteca Legislativa de representantes del partido radical. Chaco, Argentina.

Cámara de Diputados de la Provincia del Chaco (2010). Proyecto de la Comisión de Educación, Cultura y Biblioteca Legislativa de representantes del partido peronista. Chaco, Argentina.

Cámara de Diputados de la provincia del Chaco (2010). Ley de Educación Provincial No. 6.691. Chaco, Argentina.

Cámara de Diputados de la provincia del Chaco (2014). Ley de Educación Provincial No. 7.446. Chaco, Argentina.

Comisión de Seguimiento (2012). Anteproyecto No. 4.372 de Ley de Educación Pública de Gestión Comunitaria Indígena. Chaco.

Datachaco.com (26 de agosto de 2013). Peligra la estabilidad de 1000 docentes. [En línea]. http://www.datachaco.com/noticias/ view/25121.

Gómez, C. y Hadad, G. (2009). Formas de manifestación de la emergencia indígena en Argentina. Las estrategias de las organizaciones de los pueblos qom (toba) y mapuche en sus escenarios provinciales. Memorias del XXVII Congreso ALAS 2009 "Latinoamérica Interrogada", Buenos Aires, Argentina.

Feldfeber, M. (comp.) (2009) Autonomía y gobierno de la educación. Perspectivas, antinomias y tensiones. Buenos Aires: Aique.

Guarino, G. (2010). Estrategias identitarias para la resistencia étnica en las organizaciones indígenas Qom del Chaco, RevMad, 22, 56-72.

Medina, M. y Hecht, A. C. (2015). Debates en torno a la Ley de Educación Pública de Gestión Comunitaria Bilingüe Intercultural Indígena en Chaco, Praxis Educativa, vol. 19, 2, 34-42.

Hecht, A. C. (2014). Demandas pendientes y logros educativos. Un balance de la EIB en el Chaco entre 1987 y 2014. XI Congreso Argentino de Antropología Social, GT80, Universidad Nacional de Rosario, 23 al 26 de julio. Recuperado el 1 de julio de 2015 de: http://www.11caas.org/conf-cientifica/comunicacionesActasEvento.php.

L'QataxacNamQompi-Asociación Civil Che'Eguera (2012). Proyecto de Ley Educación Pública de Gestión Comunitaria Indígena. Pampa del Indio, Chaco.

Ministerio de Economía-Instituto Nacional de Estadísticas y Censos (2010). Censo Nacional de Población, Hogares y Vivienda. Argentina.

Ministerio de Educación, Cultura, Ciencia y Tecnología (2014). Informe Dirección General de Planeamiento y Evaluación Educativa. Resistencia, Chaco.

Poder Ejecutivo de la Provincia del Chaco (2010). Proyecto de Ley No. 4.372 de Educación Pública de Gestión Social Indígena. Chaco, Argentina.

Ramírez, I. (2014). Otro contexto, nuevos significados: la construcción de los sentidos del trabajo docente en una escuela de modalidad bilingüe intercultural. En: D. Veiravé (comp.). Mirar la escuela secundaria desde el trabajo docente (pp.113-132). Corrientes: Eudenne. 
Registro de campo: Debate entre referentes indigenas, dirigentes de sindicatos docentes y legisladores de la Comisión de Educación de la Cámara de Diputados de la provincia del Chaco (2013, agosto).

Rosso, L; Artieda, T. y Luján, A. (2016). Universidad y pueblos indígenas del Chaco. Análisis de una política de inclusión, participación e interculturalidad. En: D. Mato (coord.). Educación superior y pueblos indígenas en América Latina. Experiencias, interpelaciones y desafíos (pp. 371-390). Buenos Aires: Eduntref.
Saforcada, F. (2009). Paradojas de la autonomía escolar en la reforma educativa argentina de los '90. En: M. Feldfeber (comp.). Autonomía y gobierno de la educación. Perspectivas, antinomias y tensiones (pp. 129-163). Buenos Aires: Aique.

Santos, S. (2010) Para descolonizar Occidente. Más allá del pensamiento abismal. Buenos Aires: Clacso, Prometeo Libros.

\section{Diálogo del conocimiento}

Esta reflexión es muy pertinente en la medida que se centra en comprender la búsqueda de autonomía educativa de algunos pueblos indígenas del Chaco (qom, wichí y moqoit) en Argentina, en un momento en el que este anhelo de educación propia en este país es de menor divulgación que la de otros en América Latina.

En el artículo se analiza la lucha por una educación propia que trata de reconocerles a los indígenas en Argentina el derecho a la educación en sus lenguas y a la formación de docentes indígenas; es a partir de 1987 cuando se desarrolla una historia de educación bilingüe intercultural. En el artículo se hace un recorrido detallado por la legislación argentina que contempla las demandas para la educación propia de estos pueblos. Es novedoso su abordaje de las diferencias entre los mismos grupos indígenas participantes y con el Estado.

Se da cuenta de las regulaciones específicas en cuanto a escuelas de gestión indígena como una forma de organizar la intervención y asegurarla desde organizaciones y comunidades indígenas en los establecimientos. Sin embargo, dichos logros no se han dado al margen de dilemas de la pertinencia cultural y de la selección de maestros. Dichos debates, según los autores, hacen evidente que el pensamiento colonial estaba siendo sacudido, y que la invisibilidad se encontraba en un ininterrumpido y obstinado proceso de emergencia.

La manera de presentar las políticas a favor de la autonomía educativa es importante porque da cuenta de conflictos internos y tensiones políticas que desmarcan una idealización de las luchas de los movimientos sociales, en general, e indígenas, en particular, y como lo mencionan la autora alerta respecto a que el pensamiento colonial no está solamente del lado de los no indígenas.

Interesantes debates, como el remplazo del término social por el de comunitario -mayor autonomía indígena-, y el reconocimiento del Consejo Comunitario Indígena como la figura principal para asegurar la participación de las comunidades están presentados de manera clara y argumentada, y son aportes fundamentales que los autores ofrecen en este acercamiento a un fenómeno de reciente data en la historia del continente y a sus movilizaciones indígenas.

Sandra Guido Guevara 